\title{
AS REDES TÉCNICAS DO SANEAMENTO
}

\section{Sanitation Technical Networks}

Emilia Wanda Rutkowski

Bióloga (UFMG), Professora doutora da Faculdade de Engenharia Civil e Arquitetura e Urbanismo/UNICAMP, Vice-Chefe do Departamento Saneamento e Ambiente, Coordenadora do Laboratório FLUXUS/DSA/FEC/UNICAMP e da Coordenadoria de Ação Comunitária PREAC/UNICAMP.

\section{Graziella Cristina Demantova}

Arquiteta e Urbanista (PUC-Campinas, 1999), Mestre em Engenharia Agrícola (FEAGRI/UNICAMP, 2003) e doutora em Engenharia Civil, ênfase Saneamento e Ambiente (FEC/ UNICAMP, 2009), Pesquisadora Colaboradora no Depto. de Saneamento e Ambiente da Faculdade de Engenharia Civil e Arquitetura e Urbanismo da UNICAMP e pesquisadora do Laboratório FLUXUS/FEC/UNICAMP na área temática Ordenamento Territorial, Grupo Áreas de Preservação Permanentes.

\section{Alessandro Sanches Pereira}

Tecnólogo em Saneamento (UNICAMP), Mestre em Gestão e Politica Ambiental (Lund University, Suécia), doutorando da Faculdade de Engenharia Civil, Arquitetura e Urbanismo (UNICAMP). Pesquisador do Laboratório FLUXUS/FEC/ UNICAMP na área temática Ecodesign, Ecologia Industrial e Inovação Social, Grupo Ecologia Industrial. Professor da disciplina Planejamento Ambiental no Centro Universitário SENAC para a graduação em Engenharia Ambiental.

Endereço:* Faculdade de Engenharia Civil Unicamp Departamento de Saneamento e Ambiente - Av. Albert Einstein, 951 Caixa Postal: 6021 - CEP: 13083-852 - Campinas - SP

\section{RESUMO}

As péssimas condições sanitárias das cidades industriais as transformaram de pólo irradiador de riqueza a foco irradiador de doenças. Desde então há uma busca incessante pela melhoria da qualidade do meio. A complexidade das relações urbanas sobre o espaço define a bacia ambiental como uma unidade territorial de gestão. As redes técnicas de saneamento são apresentadas como instrumento para a gestão municipal compartilhada de saneamento como propõem as Políticas Nacionais de Saneamento e Resíduos Sólidos.

Palavras-chave: instrumento de gestão, município, qualidade ambiental, água potável, efluentes, águas pluviais, resíduos sólidos.

${ }^{1}$ FLUXUS/DSA/FEC/UNICAMP - rua Albert Einstein, 957. Cidade Universitária Zeferino Vaz. Barão Geraldo.13082.853 CAMPINAS/SP. emilia@fec. unicamp.br. www.fluxus.fec.unicamp.br

\footnotetext{
ABSTRACT

Deteriorating health conditions of the industrial cities transformed them from pole of wealth to focus of diseases. Since then, there is a relentless quest for improvement of the environmental quality. The complexity of urban relations on space sets environmental basin as a unit of territorial management. The sanitation technical networks are presented as a tool for shared
}

municipal management sanitation as the Sanitation and Solid Waste National Policies proposed.

Key-words: management tool, municipality, environmental quality, potable water, sewage, stormwater, solid waste.

\section{INTRODUÇÃO}

Ao surgirem, as cidades industriais, que deveriam ser pólo irradiador da nova riqueza, tornaram-se focos irradiadores de doenças por suas péssimas condições sanitárias, levando a uma busca pela salubridade do meio, que segundo Foucault:

"Salubridade não é a mesma coisa que saúde, e sim o estado das coisas e seus elementos constitutivos, que permitem a melhor saúde possível dos indivíduos. E é correlativamente a ela que aparece a noção de higiene pública, técnica de controle e de modificação dos elementos materiais do meio que são suscetíveis de favorecer ou, ao contrário, prejudicar a saúde. Salubridade e insalubridade são o estado das coisas e do meio enquanto afetam a saúde; a higiene pública - no século XIX, a noção essencial da medicina francesa - é o controle político científico deste meio" (FOUCAULT, 1982).

Por esta perspectiva, as cidades brasileiras são saneadas no início do século XX com ações para os corpos d'água que visavam disciplinar a sociedade para o "comportamento civilizado". Na segunda metade do século XX, as ações de saneamento encontram justificativa no âmbito técnico-econômico (RUTKOWSKI, 1999). O conjunto de ações praticadas, que ficam conhecidas como saneamento básico a partir do PLANASA, é definir áreas hídricas com função de abastecedoras de água "bruta", tratar as águas "brutas", canalizar as águas "servidas" e definir áreas hídricas com função de receptoras de águas "servidas". Rutkowski, Lessa e Oliveira (1999) ponderam que este modelo racionalista é centrado na perspectiva da inesgotabilidade dos recursos naturais conduzindo à adoção de um padrão de consumo quantitativo. Este enfoque tecnicista não responde os "males" sócio-economicos e ambientais, entretanto segundo Pereira (2007) induz a um modo de pensar que considere as diferenças e inter-relações não só culturais, mas também ambientais, econômicas, sociais, territoriais e institucionais.

A qualidade do meio, segundo Baumol \& Oates (1975) depende diretamente de dois fatores: o impacto da ação antrópica e o esforço dedicado para minimizar esse mesmo impacto, pois uma paisagem muito modificada ou artificializada perde sua capacidade de resiliência natural (FORMAN E GODRON, 1986). Para Stern (2007), o custo para minimizar os impactos em curso é ainda menor que o prejuízo causado diretamente por eles, entretanto sugere que, em se mantendo o nível atual, as conseqüências negativas em longo prazo para o bem-estar humano poderão atingir de 5 a $20 \%$ do produto interno bruto planetário.

As mudanças na qualidade ambiental eram consideradas externalidades intrínsecas ao sistema produtivo. Atualmente, a qualidade 
ambiental é tratada como uma commodity nos negócios estando, de acordo com Hawken et al (1999), sujeita às pressões do mercado - consumo e concorrência. $\mathrm{O}$ aumento dos investimentos para o setor de saneamento e o ordenamento proporcionado por seu novo marco jurídico - Política Nacional de Saneamento Básico [PNSB] —, ao estabelecer novas condições para a universalização dos serviços no Brasil, buscam consolidar um novo ciclo mais sustentável para o saneamento, que promova "alternativas de gestão que [inclusive] viabilizem a auto-sustentação econômica e financeira dos serviços de saneamento básico" (LF 11.445/07, Art. 20, Incisos V, IX e X).

A Política Nacional de Saneamento Básico, ao dialogar com a Política Nacional de Saúde e com as Políticas Nacionais Urbana, de Recursos Hídricos e Meio Ambiente sob a Constituição Federal de 1988, aponta para um modelo mais sustentável, que trata o tema de forma sistêmica, interligada e interdependente, baseado no bem estar humano e na qualidade ambiental, ou seja, na relação entre as ações das atividades humanas e os fluxos ecossistêmicos. Esta relação entre a velocidade das ações antrópicas e a resiliência do meio mede as perturbações ambientais. Neste contexto, os princípios da PNSB incentivam as redes técnicas de saneamento.

\section{Qualidade Ambiental}

Victor Lebow (1955) preconizou a redistribuição de riquezas como um processo de aumento do consumo, não relacionado à capacidade suporte do sistema natural. Para ele o combate ao desemprego resultaria da intensificação de demanda por bens e serviços, baixando os juros e estimulando investimentos. Se houvesse excesso de população para Lebow bastaria fomentar o crescimento econômico. A transição sócio-econômico-cultural resultante reduziria as taxas de nascimentos. As questões ambientais seriam resolvidas a contento com a Curva Ambiental Kuznets (EKC) . No mundo urbano-industrial, a EKC parecia prescindir da dinâmica ecossistêmica - a interrelação entre os entes bióticos e abióticos, suas funções e fluxos de informações. Entretanto, poluir uma área ou extrair recursos, como a água, de uma região por aparente excesso para usar em outra com escasso suprimento, impõe novas relações territoriais, novas limitações em áreas antes equilibradas e sem vinculo estreito, a priori, cultural ou econômico. A sustentabilidade do desenvolvimento preconiza a necessidade de encontrar meios de produção, distribuição e consumo dos recursos existentes de forma mais coesiva, economicamente efetiva, ecologicamente viável, socialmente justa e territorialmente planejada (PEREIRA, 2007; DEMANTOVA, 2009; RUTKOWSKI, 1999).

É inexorável a busca pela sustentabilidade do desenvolvimento, apesar da dificuldade na sua operacionalização. Bossel (1998) remete à inexistência de uma razão ou forma única de valorar a sustentabilidade para incorporá-la nas práticas diárias das pessoas. No outro extremo, apontamos a necessidade de um novo modelo civilizatório. Guimarães (2007) propõe um novo modelo de desenvolvimento baseado em ações mais direcionadas à qualidade ambiental e de vida do que à economia, de modo a evitar a insustentabilidade. Segundo Weingartner (2001), a definição de qualidade ambiental "abrange o universo de valores que se diversificou, e por vezes, a necessidade de se estabelecer um senso comum, torna-se uma tarefa difícil de realizar". Para o autor, a qualidade ambiental deve ser entendida não somente como um meio físico ecologicamente equilibrado, mas também como "um meio ambiente humano onde os anseios e desejos dos indivíduos, respeitando a diversidade e a individualidade, ultrapassam o meio físico em si".

Para Leonardo Freire de Mello (2007), o conceito de qualidade ambiental está intrinsecamente ligado ao de qualidade de vida e referese à capacidade e às condições do meio em atender às necessidades de seus habitantes. Dentro desse contexto, a qualidade ambiental e de vida depende não só das áreas verdes e outros recursos naturais, mas de todos os equipamentos existentes, das condições habitacionais, das infra-estruturas, ou seja, todos os elementos que formam o espaço das cidades precisam integrar bem-estar humano e preservação dos ecossistemas. O diálogo da sustentabilidade ambiental com a salubridade ocorre, através dos serviços de saneamento, tanto no estímulo ao desenvolvimento local, à proteção ambiental e eficiência econômica, quanto na inovação tecnológica, em busca da melhoria da qualidade de vida (RUTKOWSKI \& PEREIRA, 2009).

\footnotetext{
${ }^{2}$ Lei Federal 11445/07

${ }^{3}$ uma relação positiva entre melhoria ambiental e aumento do Produto Interno Bruto (PIB): a poluição inicialmente aumenta, mas depois atinge um máximo e, eventualmente, declina. Carson (2010) sugere que a pesquisa do Banco Mundial, a partir de um trabalho publicado em 1991 por Grossman \& Krueger, aportando diversas variáveis socioeconômicas para a correlação com qualidade ambiental foi pano de fundo para o debate da participação do México na NAFTA (North American Free Trade Agreement)
}

\section{Bacia Ambiental}

A integração entre infra-estrutura física e ecossistema se estrutura em redes técnicas que apresentam a distribuição territorial e o acesso aos recursos naturais. A análise espacial, a partir das redes técnicas, privilegia as relações sociais de uso e ocupação das terras, ao apreender os fenômenos espaciais em sua totalidade, não apenas o espaço absoluto dos atributos físicos delimitados geograficamente. Esta perspectiva tem na bacia ambiental uma unidade territorial para compreender a organização e produção do espaço urbano através da complexidade das relações que transformam constantemente o território.

A bacia ambiental proposta por Rutkowski (1999), é “(...) um espaço territorial de conformação dinâmica, cujos limites são estabelecidos pelas relações ambientais de sustentabilidade de ordens ecológica e social" e não apenas por limites geográficos, cuja análise não permite o entendimento real das forças condicionantes da degradação da qualidade ambiental e de vida nas cidades. Ainda segundo a autora:

"A bacia ambiental ao relativizar o espaço fisico, flexibilizando seus limites, privilegia as inter-relações nos diversos niveis, permitindo a análise holística/global e dinâmica da situação quando o foco de mira é a área urbanizada - um espaço antropizado. É proposta como um conjunto de inter-relações entre o ambiente fisico-químico-geológico e o meio biótico, organizadores do desenho natural da paisagem, ditadas pelas ações antrópicas, circunscrevendo, em seus limites, as drenagens naturais elou antropizadas pelas ações, neste caso, do saneamento. É um espaço territorial de conformação dinâmica, cujos limites são estabelecidos pelas relações ambientais de sustentabilidade de ordens ecológica e social” RUTKOSWKI (1999)

O reconhecimento das dinâmicas socioambientais do território e a identificação dos serviços ambientais induz um processo de gestão estratégico, prospectivo e cíclico (RUTKOWSKI, 1999). O caráter estratégico reside na possibilidade de se realizar o planejamento, pelo diagnóstico da realidade do espaço urbano, aplicando os meios disponíveis com a finalidade de alcançar objetivos específicos. "Prospectivo porque ao buscar a reabilitação e a manutenção da integridade fisica, química e biológica do meio - a sua sustentabilidade - examina as inter-relações entre os objetivos do sistema urbanizado desenvolvendo alternativas que orientem o planejamento pelos segmentos da sociedade em direção a um conjunto integrado de metas ambientais" (PETAK, 1980).

O processo de gestão é cíclico e contínuo pois os resultados realimentam

o pr
obje

obje

$\operatorname{Rec}$

As

hun

taçì

na

que

dos

tura

e de

San

eco

gun

ver

con

mer

de $t$

entr

fici

\section{Cor}

sum

iste

par

sum

aml 
o processo "(...) em ciclos de curto prazo, propiciando uma paisagem objetiva e acertada a longo prazo” (SANTOS, 1998).

\section{Redes Técnicas de Saneamento}

As infra-estruturas para Milton Santos (1996) são o trabalho humano materializado e geografizado na forma de casas, plantações, caminhos. Já o meio ecológico é a base física territorial na qual as pessoas estabelecem relações de uso e de trabalho, que apesar de não ser mais a natureza selvagem, ainda possui atributos naturais que devem ser preservados e melhor utilizados. O grau de integração e permeabilidade entre a infra-estrutura e o meio ecológico irá influenciar na qualidade ambiental e de vida dos territórios.

Santos (1985) questiona a validade da distinção entre o meio ecológico e as infra-estruturas como elementos do espaço. Segundo sua argumentação, "Na medida em que as infra-estruturas se somam e se colam ao meio ecológico, e se tornam na verdade uma parte inseparável dele, não seria uma violência considerá-los como elementos distintos? Ademais, a cada momento da evolução da sociedade, o homem encontra um meio de trabalho já constituido sobre o qual ele opera e a distinção entre o que se chamaria natural e não natural se torna artificial".

Concordando com a indagação feita por Milton Santos e assumindo que o meio ecológico é um tipo de infra-estrutura existente, que desempenha importantes e diferenciadas funções para a manutenção e melhoria da sustentabilidade urbana, assume-se que tais estruturas na realidade são as redes técnicas ambientais existentes nas cidades. Mesmo não estruturadas to- talmente, seus fixos e fluxos existem em graus diferenciados de adequação ao lugar e às dinâmicas sociais existentes.

As redes técnicas são formadas por um sistema integrado de objetos técnicos (fixos no espaço) e de fluxos (matéria, serviços e informação em circulação) que criam as conexões entre os objetos técnicos no território. Estas conexões podem ser físicas e invisíveis. Sempre que existir infra-estrutura física e transporte de serviços, matérias e informação circulando nas estruturas há redes técnicas. Tais redes, além de constituíremse na base física de produção do trabalho, permitem o transporte de matéria, de energia ou de informação no território. A gestão destes fluxos pode evitar, minimizar ou ampliar ações que causem impactos ambientais e sociais. Apesar das redes técnicas - habitação, ambiental, educação, transportes e saneamento dentre outras - existirem no território é recente o seu reconhecimento como instrumento de planejamento.

A Política Nacional de Saneamento instituiu a obrigatoriedade dos planos municipais de saneamento, que devem fazer dialogar no âmbito do município as temáticas relativas a abastecimento de água potável, esgotamento sanitário, limpeza urbana e manejo de resíduos sólidos, bem como drenagem e manejo das águas pluviais urbanas. Cada temática constitui uma rede técnica em seu conjunto diferenciado de infra-estruturas, instalações operacionais e serviços. O tratamento destas quatro temáticas a partir da análise de suas redes técnicas permite uma visão integrada do território, das interrelações entre estas quatro redes com o meio ecológico e com a sociedade. O Quadro 1 apresenta os elementos gerais das redes técnicas de saneamento.

Quadro 1 - Elementos das redes técnicas de saneamento

\begin{tabular}{|l|l|l|}
\hline \multicolumn{1}{|c|}{ REDE } & \multicolumn{1}{|c|}{ FIXOS } & \multicolumn{1}{c|}{ FLUXO } \\
\hline $\begin{array}{l}\text { Abastecimento de } \\
\text { água potável }\end{array}$ & $\begin{array}{l}\text { mananciais, estações de tratamento de águas; } \\
\text { instalações operacionais de captação, distribuição e } \\
\text { abastecimento; economias }\end{array}$ & $\begin{array}{l}\text { água potável, } \\
\text { informação sobre } \\
\text { qualidade da água }\end{array}$ \\
\hline $\begin{array}{l}\text { Esgotamento } \\
\text { sanitário }\end{array}$ & $\begin{array}{l}\text { ponto de coleta; instalações operacionais de coleta, } \\
\text { transporte e tratamento; estações de tratamento de } \\
\text { esgotos, ponto de lançamento }\end{array}$ & efuentes \\
\hline $\begin{array}{l}\text { Limpeza urbana e e } \\
\text { manejo de } \\
\text { resíduos sólidos }\end{array}$ & $\begin{array}{l}\text { edificações (públicas, residenciais, comerciais, } \\
\text { hospitalares e industriais), postos de entrega } \\
\text { voluntária (PEV), ecopontos, cooperativas, unidades } \\
\text { de transferência ou transbordo, aterros, incineradores, } \\
\text { composteiras e usinas de reciclagem e de biogás }\end{array}$ & $\begin{array}{l}\text { resíduos sólidoś } \\
\text { qualificados, } \\
\text { acondiçonanamento sobre }\end{array}$ \\
\hline $\begin{array}{l}\text { Drenagem e } \\
\text { manejo das águas } \\
\text { pluviais urbanas }\end{array}$ & $\begin{array}{l}\text { instalaçõo operacionais de drenagem, de transporte, } \\
\text { de detenção ou de retenção de águas e de tratamento }\end{array}$ & água pluvial \\
\hline
\end{tabular}


A rede técnica de limpeza urbana e resíduos sólidos tem a maior diversidade na tipologia de resíduos, de acordo com a recente Política Nacional de Resíduos Sólidos são onze tipos de resíduos quanto a origem . Eles podem ser agrupados em cinco categorias diferentes para organização da rede quanto aos processos tecnológicos. A Figura 1 apresenta os fluxos destes processos tecnológicos. Cada momento na Figura 1 remete a uma estrutura fixa da rede. Da análise das potencialidades e fragilidades das estruturas existentes em cada rede e das compartilhadas entre elas é possível avaliar os benefícios da sua implantação, ampliação ou melhoria.

$\mathrm{O}$ reconhecimento das redes técnicas como instrumento para a gestão dos serviços municipais de saneamento permite que ecossistemas e infra-estruturas físicas sejam interconectados e espacialmente inseridos no contexto e na dinâmica social local. O cenário assim desenhado projeta as demandas e os arranjos físicos na complexidade do território, conduzindo a uma análise integradora do urbano.

${ }^{4}$ Todo prédio ou subdivisão de um prédio, com ocupação independente das demais, identificável e/ou comprovável em função da finalidade de sua ocupação legal, dotado de instalação privada ou comum para uso dos serviços de abastecimento de água e/ou esgotamento sanitário, cadastrado para efeito da cobrança [http://www.sanepar.com.br/sanepar/regulamento/TITULOII.htm]

5 material, substância, objeto ou bem descartado resultante de atividades humanas em sociedade, a cuja destinação final se procede, se propõe proceder ou se está obrigado a proceder, nos estados sólido ou semissólido, bem como gases contidos em recipientes e líquidos cujas particularidades tornem inviável o seu lançamento na rede pública de esgotos ou em corpos d'água, ou exijam para isso soluções técnica ou economicamente inviáveis em face da melhor tecnologia disponível [LF 12305/2010, art 3, item XVI]

${ }^{6}$ LF 12305/2010, art 13, inciso 1

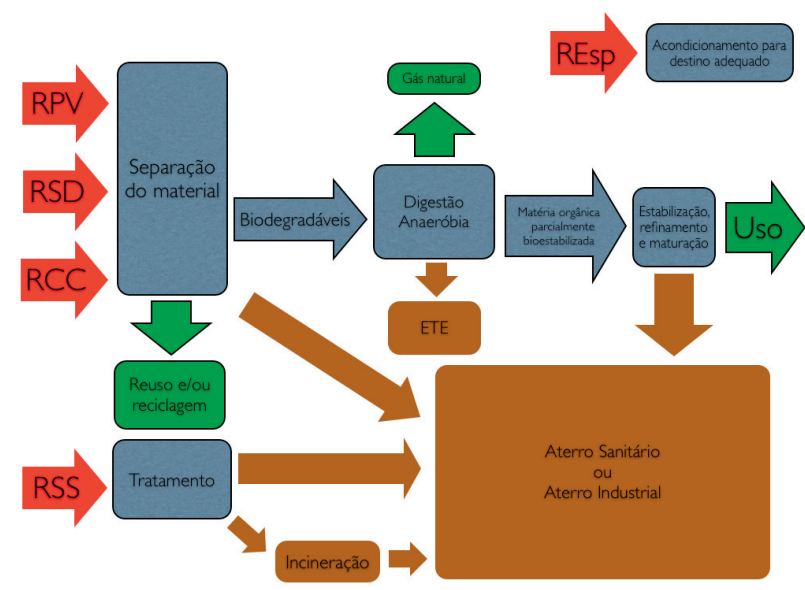

Figura 1 - Fluxos dos processos tecnológicos da Rede Técnica de Limpeza Urbana e Resíduos Sólidos [RPV - resíduos de poda e varrição, $R S D$ - resíduos sólidos domésticos, $R C C$ - resíduos de construção civil, REsp - resíduos sólidos especiais, ie, pilhas, baterias, pneus, lâmpadas fluorescentes e eletrônicos]

O reconhecimento e a constituição da rede técnica de saneamento per si não garantem a promoção de uma relação simbiótica entre os ecossistemas naturais e os antrópicos para uma prestação de serviços eficiente e de qualidade. A melhoria dos serviços prestados e o acesso universal qualificado a eles necessitam do estabelecimento das outras redes técnicas urbanas. O metabolismo aparentemente autopoiesico da cidade possui enraizado em seu território uma malha de redes técnicas interconectadas estimulando territorialidades em clusters isolados ou simbióticos. A explicitação de seus fluxos e fixos como instrumento técnico em um processo integrador de gestão compartilhada, além de ampliar e melhorar a oferta e o acesso aos serviços de saneamento no espaço urbano, conecta pessoas e lugares, estabelecendo novas e melhores relações de uso e ocupação do espaço como uma alternativa de gestão socio-ambientalmente sustentável do território.

\section{Referencias}

Carson, Richard T. The Environmental Kuznets Curve: Seeking Empirical Regularity and Theoretical Structure. In: Review of Environmental Economics and Policy. 4(1):3-23; doi:10.1093/reep/rep021. 2010

COSTA, Jodival Maurício da. Redes Técnicas e Uso Privado do Território na Amazônia: o caso da Estrada de Ferro Carajás da Companhia Vale do Rio Doce (1997-2006). Dissertação de Mestrado. Universidade Federal do Rio Grande do Sul, Instituto de Geociências. Programa de Pós-graduação em Geografia. Porto Alegre, RS. 2008.

DEMANTOVA, Graziella Cristina. Redes técnicas ambientais: diversidade e conexão entre pessoas e lugares. Tese de Doutorado. Universidade Estadual de Campinas, Faculdade de Engenharia Civil,Arquitetura e Urbanismo. Programa de Pós-graduação em Engenharia Civil - área Saneamento e Ambiente. Campinas, SP: 2009.

FOUCAULT, Michel. Microfísica do Poder. tradução Roberto Machado, Rio de Janeiro, Editora Graal, 1982.

FRANCO, Maria de AssunçÃo Ribeiro. Desenho Ambiental: Uma introdução à Arquitetura da Paisagem com o Paradigma Ecológico. São Paulo: Annablume: Fapesp. 1997.

LEBOW, Vitor. Price Competition in 1955. In: Journal of Retailing, Vol. 31 (Spring). 1955

MELLO, Leonardo Freire de. O que é lugar: Trabalhadores do conhecimento e qualidade do lugar em Campinas, SP. Tese de Doutorado. Universidade Estadual de Campinas, Instituto de Filosofia e Ciências Humanas. Programa de Pós-graduação em Demografia. Campinas, SP. 2007.

MUSSO, Pierre. A filosofia da rede. In: PARENTE, André (org). Tramas da rede. Porto Alegre: Sulinas, 2004.

PEREIRA, Alessandro Sanches 2007. The forgotten development: a discussion about the clean development mechanism and socioenvironmental sustainability. In: Kungolas, A; Brebbia, CA \& Beriatos, E (eds.), Proceedings of the Third Conference on Sustainable Development and Planning. WIT Press: Southampton, UK. vol. 2, p. 551-557. 2007.

RUTKOWSKI, Emília Wanda. Desenhando a Bacia Ambiental - Subsídios para o Planejamento das Águas Doces Metropolitan(izad)as. Tese de Doutorado. Universidade de São Paulo, Faculdade de Arquitetura e Urbanismo. Programa de Pós-graduação Arquitetura e Urbanismo, área Estruturas Ambientais Urbanas. São Paulo, SP. 1999.

RUTKOWSKI, Emília Wanda; LESSA, Simone Narciso \& OLIVEIRA, Ernestina Gomes de. Desenvolvimento Brasileiro x Meio Ambiente: trajetória da problematização da água. Revista de Ciência \& Tecnologia, Piracicaba: Unimep, v. 7, n. 14, p. 23-30. 1999

RUTKOWSKI, Emília Wanda \& PEREIRA, Alessandro Sanches. Emissão de Ttodos: mudanças no saneamento pelo clima. In: Brasil. Ministério das Cidades. Secretaria Nacional de Saneamento Ambiental. Programa de Modernização do Setor Saneamento (PMSS). Cordeiro, B.S. (org.). Lei Nacional de Saneamento Básico: perspectivas para as políticas e gestão dos serviços públicos. Brasilia, v.2, p377-389, 2009.

SANTOS, Milton. Espaço e Método. São Paulo: Nobel, 1985

SANTOS, Milton. Técnica, Espaço, Tempo: globalização e meio técnicocientífico informacional. São Paulo: Hucitec, $2^{\mathrm{a}}$ ed. 1996.

STERN, N. The Economics of Climate Change: The Stern Review. HM Treasury: UK. 2007

Viv

o c

pro

circ

anc

mo

bie

ent

ser

cati

o c

laci

cen

de

ele

Sol

\section{es}

a p

$\mathrm{dad}$

de

side

qua

um

tam

cha

(RI

se a

esc

qua

cen

den ven

\section{A}

